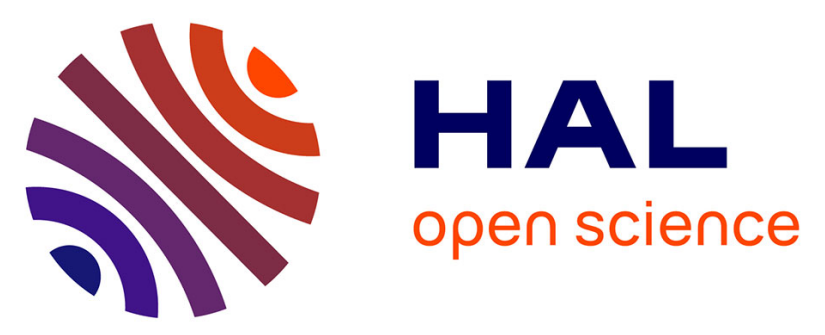

\title{
Relation between crust development and heterocyclic aromatic amine formation when air-roasting a meat cylinder
}

\author{
Alain Kondjoyan, Sylvie S. Chevolleau, Stéphane Portanguen, Jerome Molina, \\ Predrag Ikonic, Sylvie Clerjon, Laurent Debrauwer
}

\section{To cite this version:}

Alain Kondjoyan, Sylvie S. Chevolleau, Stéphane Portanguen, Jerome Molina, Predrag Ikonic, et al.. Relation between crust development and heterocyclic aromatic amine formation when air-roasting a meat cylinder. Food Chemistry, 2016, 213, pp.641-646. 10.1016/j.foodchem.2016.06.118 . hal01383873

\section{HAL Id: hal-01383873 https://hal.science/hal-01383873}

Submitted on 9 Dec 2016

HAL is a multi-disciplinary open access archive for the deposit and dissemination of scientific research documents, whether they are published or not. The documents may come from teaching and research institutions in France or abroad, or from public or private research centers.
L'archive ouverte pluridisciplinaire HAL, est destinée au dépôt et à la diffusion de documents scientifiques de niveau recherche, publiés ou non, émanant des établissements d'enseignement et de recherche français ou étrangers, des laboratoires publics ou privés. 


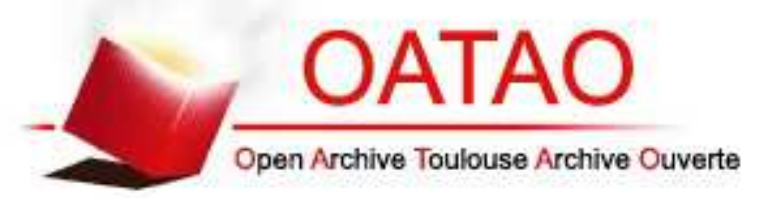

\section{Open Archive TOULOUSE Archive Ouverte (OATAO)}

OATAO is an open access repository that collects the work of Toulouse researchers and makes it freely available over the web where possible.

This is an author-deposited version published in : http://oatao.univ-toulouse.fr/ Eprints ID : 16256

To link to this article : DOI : 10.1016/j.foodchem.2016.06.118 URL : http://dx.doi.org/10.1016/j.foodchem.2016.06.118

To cite this version : Kondjoyan, Alain and Chevolleau-Mege, Sylvie and Portanguen, Stéphane and Molina, Jérôme and Ikonic, Predrag and Clerjon, Sylvie andDebrauwer, Laurent Relation between crust development and heterocyclic aromatic amine formation when air-roasting a meat cylinder.(2016) Food Chemistry, vol. 213. pp. 641-646. ISSN 0308-8146

Any correspondence concerning this service should be sent to the repository administrator: staff-oatao@ listes-diff.inp-toulouse.fr 


\title{
Relation between crust development and heterocyclic aromatic amine
}

\section{formation when air-roasting a meat cylinder}

\author{
Alain Kondjoyan $^{\mathrm{a}, *}$, Sylvie Chevolleau ${ }^{\mathrm{b}, \mathrm{c}}$, Stéphane Portanguen ${ }^{\mathrm{a}}$, Jérôme Molina ${ }^{\mathrm{b}, \mathrm{c}}$, Predrag Ikonic ${ }^{\mathrm{d}}$,
}

\author{
Sylvie Clerjon ${ }^{\mathrm{a}}$, Laurent Debrauwer ${ }^{\mathrm{b}, \mathrm{c}}$ \\ ${ }^{a}$ UR370 Qualité des Produits Animaux, INRA, F-63122 Saint Genès Champanelle, France \\ ${ }^{\mathrm{b}}$ INRA, UMR1331 TOXALIM, Research Center in Food Toxicology, MetaToul-AXIOM Platform, F-31027 Toulouse, France \\ 'Université de Toulouse, INPT, UPS, UMR1331, F-31062 Toulouse, France \\ ${ }^{\mathrm{d}}$ Institute of Food Technology, University of Novi Sad, Bulevar cara Lazara 1, 21000 Novi Sad, Serbia
}

\begin{abstract}
A B S T R A C T
The meat crust that develops during cooking is desired by consumers for its organoleptic properties, but it is also where heterocyclic aromatic amines (HAs) are formed. Here we measured HAs formation during the development of a colored crust on the surface of a beef meat piece. HAs formation was lower in the crust than previously measured in meat slices subjected to the same air jet conditions. This difference is explained by a lower average temperature in the colored crust than in the meat slices. Temperature effects can also explain why colored crust failed to reproduce the plateauing and decrease in HAs content observed in meat slices. We observed a decrease in creatine content from the center of the meat piece to the crust area. In terms of the implications for practice, specific heating conditions can be found to maintain a roast beef meat aspect while dramatically reducing HAs content.
\end{abstract}

\section{Introduction}

Cooking meat forms trace amounts of heterocyclic aromatic amines (HAs). The effects of HAs on human health have been widely investigated, and while the literature is not unanimous on the associations between HAs and human cancers, their carcino-

Abbreviations: 4,8-DiMeIQx, 2-amino-3,4,8-trimethyl-imidazo[4,5-f]quinoxa-

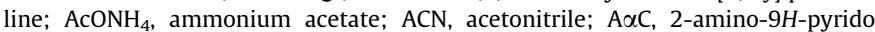
[2,3-b]indole; DMIP, 2-amino-1,6-dimethylimidazo[4,5- $b]$ pyridine; FDP, freezedried product; Glu-P-1, 2-amino-6-methyldipyrido[1,2-a:3',2'-d]imidazole; Glu-P2, 2-aminodipyrido[1,2-a:3',2'-d]imidazole; HAs, heterocyclic aromatic amines; IO 2-amino-3-methyl-imidazo[4,5-f]quinoline; IQx, 2-amino-3-methyl-imidazo[4,5-f] quinoxaline; IR, infrared; LD, Longissimus dorsi; LL, Longissimus lomborum; LT, Longissimus thoracis; MeAaC, 2-amino-3-methyl-9H-pyrido[2,3-b]indole; MeIQ 2-amino-3,4-dimethyl-imidazo[4,5-f]quinoline; MeIQx, 2-amino-3,8-dimethylimidazo[4,5-f]quinoxaline; $\mathrm{MeOH}$, methanol; MRM, multiple reaction monitoring; $\mathrm{PAH}$, Polycyclic Aromatic Hydrocarbons; PEEK, polyether ether ketone; PhIP, 2-amino-1-methyl-6-phenyl-imidazo-[4,5-b]pyridine; SM, Semimembranosus; TB, Triceps brachii; TriMeIQx, 2-amino-3,4,7,8-tetramethyl-3H-imidazo[4,5-f]quinoxaline; Trp-P-1, 3-amino-1,4-dimethyl-5H-pyrido[4,3-b]indole; Trp-P-2, 3-amino-1methyl-5H-pyrido[4,3-b]indole; TSP- $\mathrm{d}_{4}$, 3-(trimethylsilyl)-2,2',3,3'-tetradeuteropro pionic acid.

* Corresponding author.

E-mail address: alain.kondjoyan@inra.clermont.fr (A. Kondjoyan). genic effects have been proved on animals and on cell lines (Jamin et al., 2013; Ollberding, Wilkens, Henderson, Kolonel, \& Le Marchand, 2012). Moreover, even if the carcinogenic risks of moderate consumption of well-done meat appear low (Nagao, 1999; Ollberding et al., 2012), there are synergetic effects to consider. For example, a synergistic effect has been identified with Polycyclic Aromatic Hydrocarbons (PAH)/PhIP mixtures on cell lines, with an increase of the formation of DNA adducts derived from PhIP (Jamin et al., 2013). Thus, understanding and reducing HAs formation during cooking remains an important concern for consumer health.

HAs formation rate increases with temperature and depends on the time-temperature history of the surface region, i.e. the "crust", where HAs are formed. Crust development also generates the specific roasted and grilled flavours and colour desired by consumers. Several kinetic models of HAs formation and degradation have been developed in liquid and meat juice systems (Arvidsson, Van Boekel, Skog, \& Jägerstad, 1997; Arvidsson, van Boekel, Skog, Solyakov, \& Jägerstad, 1999) as well as in meat slices subjected to jets of superheated steam or dry air in the $150-250{ }^{\circ} \mathrm{C}$ temperature range (Kondjoyan et al., 2010a, 2010b). Concentrations of four of the studied HAs, i.e. IQx, MeIQx, 4,8-DiMeIQx and PhIP, follows regular kinetic patterns. HAs degradation was studied 
in a meat juice model system at 200 and $225^{\circ} \mathrm{C}$ (Arvidsson et al., 1999). In meat slices, HAs formation increases with treatment time and temperature during the first $10 \mathrm{~min}$ of treatment (Kondjoyan et al., 2010a, 2010b), after which HAs concentration either plateaus or decreases at temperatures $\geqslant 200{ }^{\circ} \mathrm{C}$. The increase in the formation of 4 HAs (MeIQx, PhIP, norharman and harman) in function of the temperature and the cooking time has also been shown recently by Gibis, Kruwinnus, and Weiss (2015) in fried bacon. Nevertheless, it is difficult to compare the concentrations of HAs because of the differences in composition between the relatively lean beef and pork rather rich in fat. No degradation was observed at $175^{\circ} \mathrm{C}$. At $200-250^{\circ} \mathrm{C}$, HAs degradation is dependent on type of HAs and gas humidity. In our previous experiments in meat slices, temperature was uniform throughout the meat, and the whole slice can be considered 'crust'. Moreover, the experiments were limited to $20 \mathrm{~min}$. These parameters are key factors when comparing HAs formation in liquid and solid media. However, the situation is different during the development of a crust on the surface of a meat piece during grilling or roasting. In these practical conditions, strong temperature and water gradients under the surface of the meat cut lead to crust formation and thickening.

Creatine and creatinine are known to be common precursors to the formation of all HAs (Bordas, Moyano, Puignou, \& Galceran, 2004; Gibis \& Weiss, 2010; Nagao, 1999). For example, half of the carbons of PhIP come from creatine and the other half from phenylalanine (Zöchling \& Murkovic, 2002). Creatine and creatinine also play a major role the formation of IQx and its related derivatives (Borgen, Solyakov, \& Skog, 2001). In meat, the concentration of creatine is about tenfold the concentration of creatinine. Creatine dehydration occurs spontaneously and non-enzymatically in the muscle to form creatinine (Purchas, Rutherfurd, Pearce, Vather, \& Wilkinson, 2004), but this reaction is strongly promoted by increasing meat temperature (Mora, Sentandreu, \& Toldra, 2008), which means cooking meat decreases creatine/creatinine ratio (Harris, Lowe, Warnes, \& Orme, 1997; Mora et al., 2008). Model systems can be used to modulate the reaction precursors to determine their effect on the formation of different HAs, which cannot be done in meat pieces (Arvidsson et al., 1997; Arvidsson et al., 1999; Bordas et al., 2004; Kondjoyan et al., 2010a, 2010b).

This paper aims at connecting HAs formation to the mechanisms which are responsible for crust formation. A special device and procedure were used to accurately control a thermal treatment mimicking the roasting of beef meat (Portanguen, Ikonic, Clerjon, \& Kondjoyan, 2014). Creatine content was also measured from the center of the meat piece out to the area of crust formation to assess its potential correlation with the formation of HAs such as PhIP or IQx. Specific heating conditions were also looked for in order to maintain the roasted aspect on the surface of beef meat while reducing HAs under a situation which mimics the baking of beef meat in a forced-convection oven.

\section{Materials and methods}

\subsection{Sample preparations, heat treatments, and thickness measurements}

Longissimus thoracis muscles were taken from carcasses of 18month-old heifers immediately after slaughter. The muscles were cut into big pieces, aged for 12 days under vacuum packed conditions, then frozen and stored at $-20^{\circ} \mathrm{C}$. Thermal Treatment and temperature measurement were performed using: (1) an open jet system which enables IR measurement of surface temperature, and (2) a specific device that partially compensates for the heat shrinkage of the sample.
A cylinder of meat, $48 \mathrm{~mm}$ in diameter and $50-55 \mathrm{~mm}$ in height, was accurately cut from big pieces of the previous muscles, following the procedure detailed in Kondjoyan et al. (2010a, $2010 \mathrm{~b})$. The meat cylinder was placed in a support formed by a bigger hollow cylinder made in PEEK ${ }^{\circledR}$. The cylindrical meat sample was pushed by a spring fixed to a disc located at the bottom of the device onto a grid fixed by a lid at the top of the device. Spring contraction was adjusted using four screws located under the disc. The support was then placed under the center of an open jet system. During heat treatment, air temperature at the pipe outlet was either $160,190,225$, or $260^{\circ} \mathrm{C}$, and distance (d) between sample surface and pipe outlet was set at $36 \mathrm{~mm}$. Actual temperatures reached on the surface of the meat sample are given in Table 1. Heating was stopped by sliding the support beneath a $45-$ $55 \mathrm{~m} \mathrm{~s}^{-1}$ jet flow of cold air (temperature $3-5^{\circ} \mathrm{C}$ ) produced by a Ranque-Hilsch vortex tube. Meat surface temperature was measured continuously throughout thermal treatment using a calibrated IR pyrometer (Kondjoyan et al., 2010a, 2010b). During heating and cooling, the temperatures of the air jet impacting the meat were measured using a thermocouple fixed to the PEEK ${ }^{\circledR}$ cylinder and set $2 \mathrm{~mm}$ above the meat surface. After cooling, the meat cylinder was removed from the support taking every precaution not to tear away any crust while withdrawing the surface grid. Samples were used to analyse crust thickness and HAs content.

To measure the thickness of the colored crust, the top of one half of the meat sample was cut perpendicularly to the cylinder axis such that the thickness of the slice was equal to the thickness of the brown-colored crust plus a further 2-3 mm of "non-browncolored" crust. A set of pictures of crust area was taken using a camera $(\times 10$ zoom $)$ associated to binoculars $(\times 1.6$ or $\times 2$ magnification) and a $100 \times 0.1=10-\mathrm{mm}$ scale (PYSER-SGI, UK). The thickness of the colored area was measured visually from the binocular images. Measurements were taken in at least five crust locations to obtain repeatable average and standard deviation values. In a first step, GIMP 2.6 software was run on the image to accurately separate the brown-colored crust area from the non-brown-colored area following the irregular border. In a second step, a calibration of lengths was done using the pictures of the reference length taken in each image to avoid any difference in image resolution. In a third step, average crust thickness and its standard deviation were calculated from all the acquisitions obtained on different portions of crust (specific programs developed using Matlab 7.0 ${ }^{\circledR}$ and its image processing toolbox).

\subsection{Quantification of creatine}

Creatine content was measured on meat cylinders exposed to the hot air jet at $192{ }^{\circ} \mathrm{C}$ for either 20 or $60 \mathrm{~min}$. After the treatment, four $5 \mathrm{~mm}$-thick slices of meat were cut from the top of the cylinder perpendicularly to jet direction (Fig. 1, right). Creatine was measured by NMR in raw and cooked meat samples. Microsamples $(0.2 \mathrm{~g})$ were ground in $\mathrm{Na}_{2} \mathrm{HPO}_{4} / \mathrm{NaH}_{2} \mathrm{PO}_{4} \cdot 12 \mathrm{H}_{2} \mathrm{O}$ buffer at $\mathrm{pH} 5.0$ (Acros Organics, Geel, Belgium). After $12 \mathrm{~h}$ of rest, the solution was filtered and centrifuged for $10 \mathrm{~min}$ at $14,500 \mathrm{~g}$ at room temperature. Then, a $0.6 \mathrm{~mL}$ aliquot of the supernatant was assayed by ${ }^{1} \mathrm{H}$ NMR spectroscopy. Creatine was characterized by two characteristic resonance signals: a singlet resonance at $3.03 \mathrm{ppm}\left(\mathrm{CH}_{3}\right)$ and a singlet resonance at $3.92 \mathrm{ppm}\left(\mathrm{CH}_{2}\right)$. The integration of these

Table 1

Heating times and temperatures corresponding to HAs measurements.

\begin{tabular}{lll}
\hline $\mathrm{T}_{\text {pipe }}\left({ }^{\circ} \mathrm{C}\right)$ & $\mathrm{T}_{\text {jet }}\left({ }^{\circ} \mathrm{C}\right)$ & Cooking time (min) \\
\hline 160 & $120-130$ & 20,40 and 90 \\
190 & $150-160$ & 20,40 \\
225 & $190-200$ & $20,30,60$ and 90 \\
260 & $200-220$ & $20,40,60$ and 90 \\
\hline
\end{tabular}



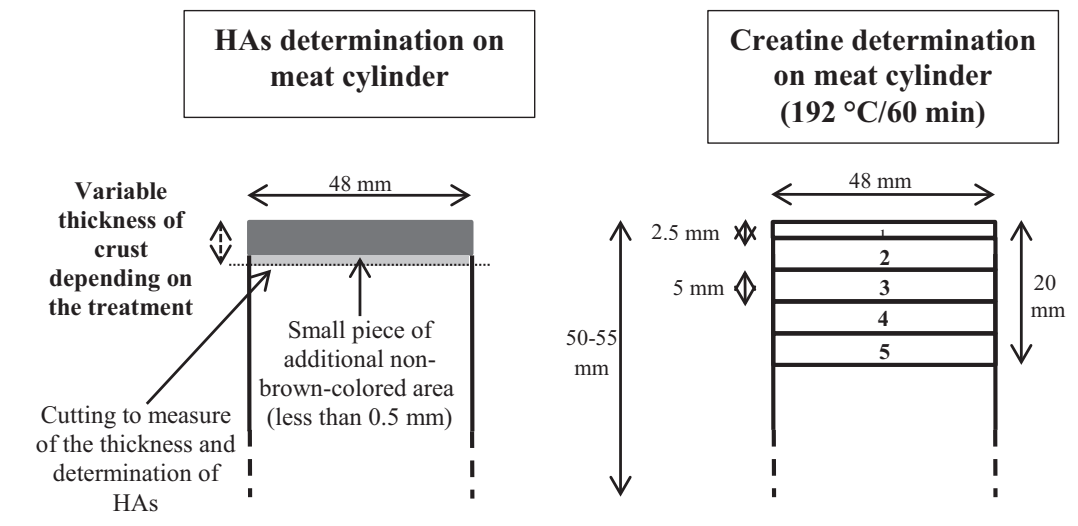

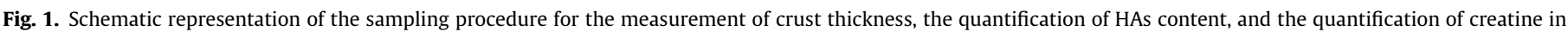
five slices of meat.

two signals was proportional to the number of protons. Quantifications were made with respect to a closed capillary containing TSP-d4 (3-(trimethylsilyl)-2,2',3,3'-tetradeuteropropionic acid, Sigma-Aldrich, Saint-Quentin-Fallavier, France) measured relative to a $1.76 \mathrm{mmol} . \mathrm{L}^{-1}$ standard solution of creatine.

\subsection{Identification and quantification of HAs in the colored crust}

Thirteen different HAs (IQ, IQx, MeIQ, MeIQx, 4,8-DiMe-IQx, A $\alpha \mathrm{C}$ MeA $\alpha$ C, Trp-P-1, Trp-P-2, PhIP, Glu-P1, Glu-P2, DMIP) were determined by UHPLC-APCI-MS/MS based on an LC-APCI-MS/MS method developed for chicken meat (Chevolleau, Touzet, Jamin, Tulliez, \& Debrauwer, 2007) and since adapted for analyzing beef meat samples (Kondjoyan et al., 2010a, 2010b). Meat samples were treated as described in previous papers (Kondjoyan et al., 2010a, 2010b).

Briefly, $1 \mathrm{~g}$ of lyophilized beef meat sampled from the whole cooked sample was first treated with $1 \mathrm{M} \mathrm{NaOH}$. The internal standard (TriMeIQx) was added at this stage at a concentration of $50 \mathrm{pg} / \mu \mathrm{L}$. After liquid/liquid extraction (methylene chloride, Extrelut), purification by solid-phase extraction (Oasis MCX $60 \mathrm{mg} / 3 \mathrm{cc}$ ) and evaporation to dryness, the resulting residue was re-dissolved in $200 \mu \mathrm{L}$ of the starting LC mobile phase. Separation was performed on an Accela 600 LC system (Thermo Fisher Scientific, Les Ulis, France), using a Hypersil GOLD C8 column (Thermo Fisher Scientific, $50 \times 2.1 \mathrm{~mm}, 1.9 \mu \mathrm{m})$ with prefilter and a $\mathrm{AcONH}_{4}(30 \mathrm{mM}, \mathrm{pH} 5 /$ $\mathrm{ACN} / \mathrm{MeOH}$ ) gradient elution. $5 \mu \mathrm{L}$ of the final extract was injected, and separation was performed at $30^{\circ} \mathrm{C}$ at a flowrate of $0.5 \mathrm{~mL} /$ min. MS detection was performed on a TSQ Vantage triple-stage quadrupole mass spectrometer (Thermo Fisher Scientific) using pos- itive APCI ionization based on two specific transitions for each HA. Typical working parameters were as follows: discharge APCI current, $4 \mu \mathrm{A}$; nebulizer temperature, $420^{\circ} \mathrm{C}$; heated transfer capillary temperature, $250^{\circ} \mathrm{C}$; heated transfer capillary voltage, $35 \mathrm{~V}$; sheath gas flow rate, 40 a.u.; auxiliary gas flow rate, 8 a.u. The performance of the optimized method was characterized in terms of linearity $\left(\mathrm{r}^{2}>0.99\right.$ between 1 and $\left.1000 \mathrm{pg} / \mu \mathrm{L}\right)$, repeatability of retention times $(\mathrm{RSD}=1.5-2.0 \%, \mathrm{n}=6)$ and area ratios $(\mathrm{RSD}=5-10 \%, \mathrm{n}=6)$, LoD (0.015-0.05 ng/g) and LoQ (0.05-0.2 ng/g). No matrix effect (checked by post-column addition of the 13 HAs mixture) was observed. Each cooked meat sample was extracted and analyzed in triplicate. HA contents were expressed in nanograms of compound per gram of freeze-dried product.

\subsection{Statistical analysis}

All results in Table 3 were analyzed for normal distribution and subjected to an analysis of variance using HSD Tukey-test $(\alpha=0.05)$ using the STATISTICA 12 Software (StatSoft France, France).

\section{Results and discussion}

\subsection{Variations in creatine content in the meat cylinder during heating}

In this study, results are expressed based on both dry matter (FDP) and as a function of weight of the roasted product. Results expressed on a FDP basis made it possible to track changes in creatine content regardless of juice loss variations. Results

Table 2

Creatine and creatinine levels in beef depending on cooking conditions.

\begin{tabular}{|c|c|c|c|c|c|c|}
\hline Meat & $\begin{array}{l}\text { Cooking } \\
\text { method }\end{array}$ & $\begin{array}{l}\text { Cooking } \\
\text { temp. }\left({ }^{\circ} \mathrm{C}\right)\end{array}$ & $\begin{array}{l}\text { Cooking time } \\
(\min )\end{array}$ & $\begin{array}{l}\text { Creatine } \\
(\mathrm{mg} / 100 \mathrm{~g})\end{array}$ & $\begin{array}{l}\text { Creatinine } \\
(\mathrm{mg} / 100 \mathrm{~g})\end{array}$ & Authors \\
\hline \multirow[t]{2}{*}{ Stewing-beef } & Raw & 1 & I & 364.5 & 7.8 & Harris et al. (1997) \\
\hline & Boiling & 98 & $10-60$ & $346.2-285.9$ & $26.1-118.8$ & \\
\hline Beef $(S T)$ & Raw & 1 & 1 & 401.0 & 5.8 & Purchas et al. (2004) \\
\hline Beef $(T B)$ & Raw & 1 & l & 329.0 & 5.6 & Purchas and Busboom (2005) \\
\hline \multirow[t]{2}{*}{ Beef $(L L)$} & Raw & I & I & 383.5 & 6.1 & Purchas et al. (2006) \\
\hline & Grilling & 71 & l & 310.6 & 43.2 & \\
\hline Beef $(L D)$ & Raw & 1 & I & 600.0 & 19.0 & Polak, Andrenšek, Žlender, and Gašperlin (2009) \\
\hline \multirow{2}{*}{$\begin{array}{l}\text { Deep frozen beef patties } \\
\quad(70 \mathrm{~g}, 8 \mathrm{~mm} \text { thick } \times 113 \times 105 \mathrm{~mm})\end{array}$} & Raw & 1 & l & $343.0^{*}$ & $9.9^{*}$ & Gibis and Weiss (2010) \\
\hline & Fried & 230 & $2-3$ & $226.9-178.5^{*}$ & $52.8-116.9^{*}$ & \\
\hline Beef $(L T)$ & Raw & 1 & I & 1 & 10.3 & Kondjoyan et al. (2010b) \\
\hline Beef $(S M)$ & Raw & 1 & i & i & 10.9 & \\
\hline \multirow[t]{3}{*}{ Beef (LT) } & Raw & i & I & 470.7 & 1 & Present study \\
\hline & Baking & 192 & 20 & 416.9 & l & \\
\hline & & 210 & 90 & 101.0 & 1 & \\
\hline
\end{tabular}

Levels based on dry matter. 
Table 3

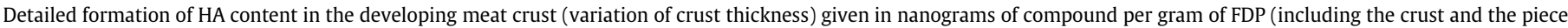

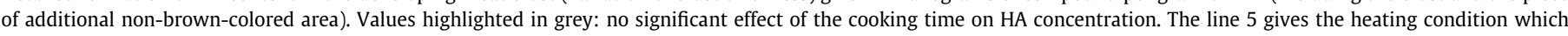
maintain the roasted aspect meat while reducing HAs content in the meat.

\begin{tabular}{|c|c|c|c|c|c|c|c|c|c|c|}
\hline Lines & $\begin{array}{l}\text { Roasting } \\
\text { time (min) }\end{array}$ & $\begin{array}{c}\text { Roasting } \\
\text { Temp }\left({ }^{\circ} \mathrm{C}\right)\end{array}$ & $\begin{array}{c}\text { Crust thickness } \\
\text { (mm) }\end{array}$ & $\begin{array}{l}\text { MeIQx } \\
\text { (ng/g FDP) }\end{array}$ & $\begin{array}{c}\text { IQx } \\
\text { (ng/g FDP) }\end{array}$ & $\begin{array}{c}4,8- \\
\text { DiMeIQx } \\
\text { (ng/g FDP) }\end{array}$ & $\begin{array}{c}\text { PhIP } \\
\text { (ng/g FDP) }\end{array}$ & $\begin{array}{c}\text { MeIQ } \\
\text { (ng/g FDP) }\end{array}$ & $\begin{array}{c}\text { DMIP } \\
\text { (ng/g FDP) }\end{array}$ & $\begin{array}{l}\text { Glu-P-2 } \\
\text { (ng/g FDP) }\end{array}$ \\
\hline 1 & 20 & \multirow{3}{*}{124} & 0.17 & $1.3 \pm 0.2$ & nd & nd & $0.3 \pm 0.1$ & nd & nd & nd \\
\hline 2 & 40 & & 0.19 & $19.4 \pm 0.6$ & $1.7 \pm 0.2$ & nd & $5.1 \pm 0.2$ & traces & nd & nd \\
\hline 3 & 90 & & 0.42 & $41.1 \pm 7.0$ & $2.3 \pm 0.1$ & $2.2 \pm 0.1$ & $5.8 \pm 0.7$ & traces & $8.7 \pm 0.9$ & 0.5 \\
\hline 4 & 20 & \multirow{2}{*}{158} & 0.38 & $10.9 \pm 5.7$ & 0.51 & traces & $3.6 \pm 1.4$ & traces & nd & nd \\
\hline 5 & 40 & & 0.72 & $13.7 \pm 1.3$ & nd & traces & $1.2 \pm 0.5$ & traces & 2.9 & trace \\
\hline 6 & 20 & \multirow{3}{*}{192} & 0.86 & $35.5 \pm 0.5$ & $2.2 \pm 0.3$ & $2.0 \pm 0.1$ & $14.5 \pm 1.5$ & nd & $6.3 \pm 0.7$ & traces \\
\hline 7 & 30 & & 1.42 & $88.5 \pm 8.8$ & $5.1 \pm 0.6$ & $5.2 \pm 0.2$ & $21.0 \pm 1.6$ & nd & $13.1 \pm 1.9$ & traces \\
\hline 8 & 90 & & 3.85 & $217.0 \pm 1.6$ & $9.8 \pm 0.3$ & $11.9 \pm 0.2$ & $98.0 \pm 2.2$ & $1.1 \pm 0.2$ & $41.0 \pm 1.5$ & $21.6 \pm 0.7$ \\
\hline 9 & 20 & \multirow{3}{*}{210} & 1.94 & $181.1 \pm 2.1$ & $10.3 \pm 0.3$ & $11.4 \pm 0.3$ & $95.0 \pm 1.7$ & $0.5 \pm 0.2$ & $27.7 \pm 0.4$ & $9.4 \pm 0.5$ \\
\hline 10 & 40 & & 2.59 & $220.4 \pm 8.6$ & $11.7 \pm 1.0$ & $14.0 \pm 0.5$ & $156.9 \pm 4.8$ & $1.8 \pm 0.2$ & $48.8 \pm 2.2$ & $24.9 \pm 1.4$ \\
\hline $11 *$ & 90 & & 5.82 & $417.0 \pm 14.8$ & $21.6 \pm 1.0$ & $26.9 \pm 0.9$ & $255.9 \pm 10.5$ & $2.7 \pm 0.2$ & $99.7 \pm 6.1$ & $48.0 \pm 5.9$ \\
\hline
\end{tabular}

*Crust too thick, not accepted by consumers.

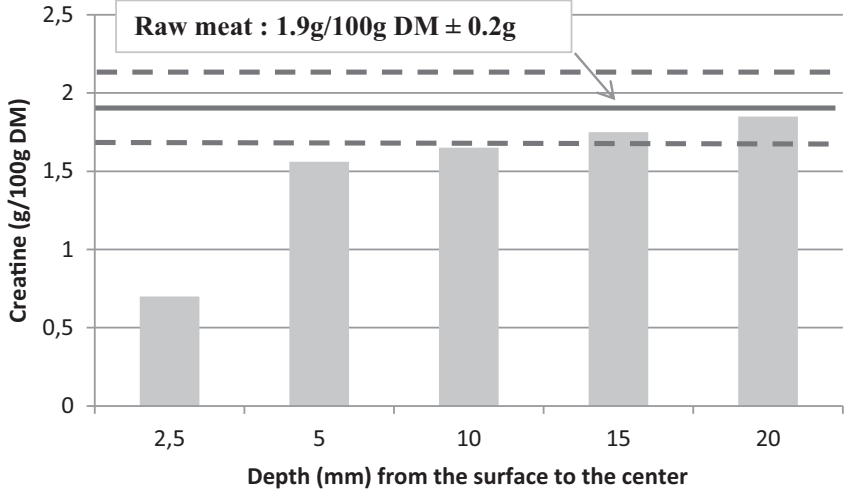

Fig. 2. Quantification of creatine at different depths in meat (subjected to a $192{ }^{\circ} \mathrm{C}$ air jet during $60 \mathrm{~min})$. Average creatine value in raw meat $(1.9 \mathrm{~g} / 100 \mathrm{~g}$ FDP) is plotted as a solid line. Dotted lines correspond to the standard deviation. For information purposes, a creatine concentration of $1.9 \mathrm{~g} / 100 \mathrm{~g}$ DM correspond to a value of creatine of $550 \pm 10 \mathrm{mg} / 100 \mathrm{~g}$ of cooked meat.

expressed on a mass of cooked product basis made it possible to compare our results with the literature. Fig. 2 plots the profile of creatine content measured from the center of the meat piece to its surface when the meat cylinder was subjected to a jet of hot air at $192{ }^{\circ} \mathrm{C}$ for $60 \mathrm{~min}$. A $20 \mathrm{~min}$ treatment led to a similar profile shape but the contents were different ( $\mathrm{ca}$. 20\% less than in Fig. 2; data not shown). At the center of the meat piece, creatine concentration was $501 \mathrm{mg} / 100 \mathrm{~g}$ cooked meat (1.85 g/100 g FDP), which matches to the concentration reported by Purchas, Busboom, and Wilkinson (2006) for raw meat (Table 2). Gibis et al. (2015) measured the creatine concentration in bacon at different scales of time and temperature, the results show a decrease in creatine concentration with increasing temperature. This is also observed in present study as a function of depth in the meat, which is connected to the decrease of the temperature. Concentration expressed as a function of FDP decreases steadily towards the meat surface and then sharply once in the colored crust.

\subsection{HAs content in the colored crust}

U-HPLC-MS/MS was able to characterize and quantify 13 HAs with better performances than achievable using classical LC-MS/
MS. Four of these HAs, namely Trp-P-1 Trp-P-2, A $\alpha \mathrm{C}$ and MeA $\alpha \mathrm{C}$, were never detected in the colored crust or only in trace amounts, while Glu-P-1 and IQ was detected in quantities close to our LoQ in the most drastic roasting conditions $\left(210^{\circ} \mathrm{C}, 90 \mathrm{~min}\right)$. Table 3 reports the concentrations of the other HAs measured in the surface area (including the colored crust plus the small portion of non-brown-colored area) of the meat cylinder.

The heat treatments can be divided into three categories according to HAs content. In the first category (lines 1, 2, 4 and 5 in Table 3), jet temperature and heating duration are less than or equal to $158{ }^{\circ} \mathrm{C}$ and $40 \mathrm{~min}$, respectively. Only MeIQx and PhIP are formed in more important quantities, with concentrations below $20 \mathrm{ng} \mathrm{g}^{-1}$ FDP for MeIQx and below $5 \mathrm{ng} \mathrm{g}^{-1}$ FDP for PhIP. The second category concerns the longest treatment at the lowest temperature $\left(124^{\circ} \mathrm{C}\right.$ for $\left.90 \mathrm{~min}\right)$ together with the shortest treatment at $192{ }^{\circ} \mathrm{C}$ (lines 3 and 6, Table 3). In this case, all the HAs are formed in significant amounts except MeIQ and Glu-P-2. The MeIQx and PhIP concentrations measured were 35-40 and 5$15 \mathrm{ng} \mathrm{g}^{-1}$ FDP, respectively. In the third category, all the HAs are formed in high amounts, except MeIQ which remained under $3 \mathrm{ng} \mathrm{g}^{-1}$ FDP (lines 7-11 in Table 3). In this category, two major HAs reach concentrations up to $416 \mathrm{ng} \mathrm{g}^{-1}$ FDP for MeIQx and to $255 \mathrm{ng} \mathrm{g}^{-1}$ FDP for PhIP.

The effect of cooking time on HAs concentration was studied from results reported in Table 3, using the HSD Tukey-test. Few effects of cooking time were not significant (values highlighted in grey in Table 3), concerning in particular the formation of PhIP at the lowest temperatures. Above $192{ }^{\circ} \mathrm{C}$, time effect was found to be highly significant, except for the specific cases of IQx at 20 and $40 \mathrm{~min}$ at a temperature of $210^{\circ} \mathrm{C}$. The effect of time $\times$ temperature was also tested for the conditions corresponding to lines 1-3 and 9-11, showing a highly significant effect of the temperature $\left(124-210^{\circ} \mathrm{C}\right)$, of the cooking time $(20,40,90 \mathrm{~min})$ and of the two combined factors on the formation of MeIQx and PhIP.

\subsection{Discussion}

The HAs concentrations measured in this study within the colored crusts of small roasts can be compared to those measured in a thin slice of beef meat subjected to superheated steam or dry air jets (Kondjoyan et al., 2010a, 2010b). The MeIQx and IQx concentrations within the colored crust of the small roasts were half the 
concentrations found in the slices at identical jet temperature and treatment duration. The proportions were more variable for the HAs known to form in a water activity-sensitive manner. The ratio of amounts of HAs formed in the colored crust versus the slice ranged from 2.0 to 9.0 for PhIP and from 0.8 to 2.0 for 4.8-DiMeIQx depending on the type of thermal treatment (dry air or superheated steam). The lower HAs content found in colored crust developed on the surface of the meat pieces compared to the thin slices can be attributed to either: (1) local differences in precursor concentrations, (2) differences in the "reactivity" of these precursors connected to the water activity in the food matrix, or (3) local differences in in-product temperature.

The first explanation cannot be connected with an initial difference in HAs precursors in the raw meat, as all the experiments were led on the same beef muscle, i.e. Longissimus thoracis. Thus, the local variation in precursors content can only be attributed to differences due to their migration over the course of the experiment. In this study, creatine concentration decreased from $1.85 \mathrm{~g} / 100 \mathrm{~g}$ FDP at the middle of the meat piece to 0.7 in the $2.5 \mathrm{~mm}$ just under the cylinder surface when the meat cylinder was roasted at $192{ }^{\circ} \mathrm{C}$ for $60 \mathrm{~min}$. The literature (Table 2 ) reports that creatine concentration decreases down to $310 \mathrm{mg} / 100 \mathrm{~g}$ during grilling (Purchas et al., 2006) and $178 \mathrm{mg} / 100 \mathrm{~g}$ during frying (Gibis \& Weiss, 2010) where the creatine likely mainly undergoes dehydration, leading to an increase of creatinine concentration. Initial creatinine content in raw meat from Longissimus thoracis muscle ranges from 8.4 to $11.4 \mathrm{mg} / 100 \mathrm{~g}$ (Kondjoyan et al., 2010b). If the increase of creatinine is proportional to the decrease in creatine, then creatinine content in the crust would be multiplied by about 30 -fold compared to the initial raw meat content. This could have important ramifications for the formation of HAs, especially PhIP, since Bordas et al. (2004) reported that a 25 -fold increase in creatinine doubled the PhIP concentration in a meat flavor model system subjected to a dry treatment at $200{ }^{\circ} \mathrm{C}$ for $30 \mathrm{~min}$, whereas there was almost no effect on PhIP when the model system was subjected to wet treatment at $170{ }^{\circ} \mathrm{C}$ for $2 \mathrm{~h}$. Moreover, during Bordas' experiments, creatine content was held constant while creatinine content varied, whereas under our more realistic conditions, creatine and creatinine contents varied in the opposite pattern. Thus, in our set-up, the relative effect of creatine and creatinine content on HAs formation on the surface of a piece of meat strongly heated and dried during crust formation remains open to debate, especially since this effect of creati(ni)ne can be mixed with that of the amino-acids. Indeed, Bordas et al. (2004) also observed a strong effect of variation in amino acids content on PhIP formation whereas we did not measure amino acids content in the crust area here.

The second explanation based on difference on precursor reactivity is supported by the fact that in previous studies, it was observed that despite a higher amount of precursors, IQx, MeIQx and 4.8-DiMeIQx formed at lower rates in meat slices than in meat juice (Arvidsson et al., 1999; Kondjoyan et al., 2010a, 2010b).

However, the third explanation seems the most likely here, since thin slices can be considered areas of high and homogeneous temperature whereas the colored crust featured sharp temperature gradients resulting in a lower mean temperature in the crust than in the slices. This difference stems directly from the development of the crust structure on the surface of meat pieces. We previously showed that crust is a complex structure displaying several distinct areas. The transition from non-crust to crust area begins at the evaporation front (Portanguen et al., 2014). Just beyond this front, liquid is replaced by vapour, but water content is still high. Therefore, water activity and temperature remain close to 1.00 and $100^{\circ} \mathrm{C}$, respectively. Water content then decreases toward the surface, which leads to areas of high-temperature gradients successively dominated by the formation of colored Maillard compounds and of HAs, respectively.
This study quantified HAs inside the colored crust. A schematic drawing of the relative thickness of the different crust areas estimated after $70 \mathrm{~min}$ of treatment at $210^{\circ} \mathrm{C}$ is given in Fig. 3 (Portanguen et al., 2014). The area where the temperature is greater than or equal to $200{ }^{\circ} \mathrm{C}$ is about $0.5 \mathrm{~mm}$ deep and thus represents less than one third of the area where the in-product temperature is over $150^{\circ} \mathrm{C}$. This illustrates the extent of the temperature gradients near the surface of the meat pieces, and also explains why no plateau or decrease in HAs quantities were observed in the colored crust, contrary to our previous studies on meat slices where HAs plateauing or degradation were observed after just $10 \mathrm{~min}$ of heat treatment (Kondjoyan et al., 2010a, 2010b). The slow HAs degradation that could occur in the $200^{\circ} \mathrm{C}$ area just under the crust surface is likely overwhelmed by the strong HAs formation in the deeper area of the meat piece.

These observations tend to confirm that the major factor driving HAs formation and degradation is time-temperature. However, water activity was also found to play an important role during experiments on meat slices where HAs formation increased with decreased water activity due to the use of dry-air jets instead of superheated steam jets (Kondjoyan et al., 2010a, 2010b). A better quantification of these different phenomena would require accurate heat and mass transfer modelling since measures are delicate due to the very thin areas which form the crust.

\subsection{Mitigation of consumer exposure to HAs}

During roasting, HAs concentrate in the upper part of the crust while other parts of the meat piece do not get hot enough (i.e. below $124^{\circ} \mathrm{C}$ ) to start generating HAs. The effect of time-temperature on HAs formation is clear in Table 3 showing that very low amounts of MeIQx and PhIP only begin to form from $158^{\circ} \mathrm{C}$ for 20 min. Indeed, the quantities of MeIQx and PhIP measured at $158^{\circ} \mathrm{C}$ for $20 \mathrm{~min}$ are approximately 35 times lower than the quantities measured at $158^{\circ} \mathrm{C}$ for $40 \mathrm{~min}$ which, in turn, are still 3-10 times lower than at $192{ }^{\circ} \mathrm{C}$ for $20 \mathrm{~min}$. The HAs concentrations expressed in Table 3 are per weight of crust based on FDP. Thus, crust mass also has to be factored into determine consumer exposure to HAs. We previously showed that the thickness of the colored crust increases linearly with time (Portanguen et al., 2014). Note that Table 3 also gives the crust thicknesses measured after the different heat treatments. Crust thicknesses greater than $3 \mathrm{~mm}$ were voluntarily discarded from analysis as not representative of common cooking practices.

The air-jet heat treatment at $158{ }^{\circ} \mathrm{C}$ applied for 40 min leads to HAs contents that can be considered very low in the thin colored crust. Thus, the real mass content of HAs can be considered negli-

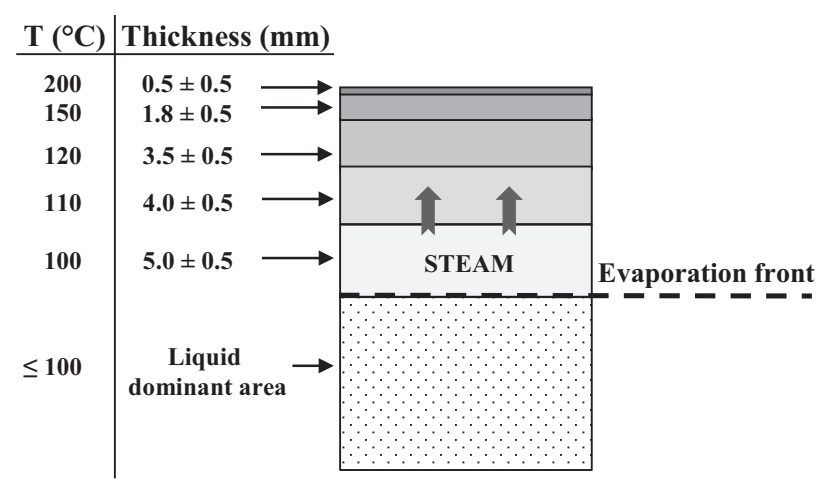

Fig. 3. Schematic representation of the thickness of the different areas in the crust after meat cylinder was subjected to the air jet heating at $210^{\circ} \mathrm{C}$ for $70 \mathrm{~min}$. These thickness values are issues from the work of Portanguen et al. (2014). 
gible even though the meat surface is visually perceived as 'crust'. In terms of practical implications, specific heating conditions can be found to maintain a roast beef meat aspect while dramatically reducing HAs content in the meat. Moreover, the fact that crust thickness increases linearly with time raises prospects for controlling crust development during the roasting process. However, this thickness increase was observed under specific air-jet situations and has yet to be confirmed for other cooking conditions. More generally, the time-course evolution of surface and under-surface temperatures depends on air-flow velocity and the heat exchanged by radiation, which vary from one set of equipment to another. Thus, specific thermal studies are needed to further determine and control the optimal conditions to ensure safe meat roasting for different types of cooking equipments.

\section{Conclusion}

Less HAs form in colored crusts developing on the surface of meat pieces than in meat slices subjected to the same time-temperature conditions. This can be explained considering the temperature of the whole slice is very rapidly reaches to air temperature whereas the crust features a sharp temperature gradient resulting in a net lower mean temperature of the crust than the surrounding air. Temperature gradients can also explain why even at the longest treatment times and highest jet temperatures, the colored crust failed to reproduce the plateauing and decrease in HAs content observed in meat slices (Kondjoyan et al., 2010a, 2010b). A decrease of creatine (which may result in an increase of creatinine) was measured from the center of the meat piece towards the area of crust formation. This decrease was further promoted by increasing the temperature, and could have impacted the formation of HAs, especially PhIP or IQx. However, the analysis of the relative effects of the different precursors of HAs, and of temperature and water activity in a complex media like meat would need more analysis and would benefit from a transfer-reaction modelling approach (Kondjoyan et al., 2014).

In terms of practical implications, we found specific heating conditions that maintain a roast beef meat aspect while dramatically reducing HAs content in the meat subjected to hot air jet conditions. However, further thermal studies will be needed to mitigate HAs formation while maintaining the roast beef meat aspect considering different types of cooking equipments. Sensory analysis will also be needed to analyse the impact of these heating conditions on savour and flavour.

\section{References}

Arvidsson, P., Van Boekel, M. A. J. S., Skog, K., \& Jägerstad, M. (1997). Kinetics of formation of polar heterocyclic amines in a meat model system. Journal of Food Science, 62(5), 911-916.
Arvidsson, P., van Boekel, M. A. J. S., Skog, K., Solyakov, A., \& Jägerstad, M. (1999) Formation of heterocylic amines in a meat juice model system. Journal of Food Science, 64(2), 216-221.

Bordas, M., Moyano, E., Puignou, L., \& Galceran, M. T. (2004). Formation and stability of heterocyclic amines in a meat flavour model system. Effect of temperature, time and precursors.. Journal of Chromatography B. Analytical Technologies in the Biomedical and Life Sciences, 802(1), 11-17.

Borgen, E., Solyakov, A., \& Skog, K. (2001). Effect of precursor composition and water on the formation of heterocyclic amines in meat model systems. Food Chemistry, $74,11-19$.

Chevolleau, S., Touzet, C., Jamin, E., Tulliez, J., \& Debrauwer, L. (2007). Dosage par LC-APCI-MS/MS des amines aromatiques hétérocycliques formées lors de la cuisson des viandes. Science des Aliments, 27(6), 381-396.

Gibis, M., \& Weiss, J. (2010). Inhibitory effect of marinades with hibiscus extract on formation of heterocyclic aromatic amines and sensory quality of fried beef patties. Meat Science, 85(4), 735-742.

Gibis, M., Kruwinnus, M., \& Weiss, J. (2015). Impact of different pan-frying conditions on the formation of heterocyclic aromatic amines and sensory quality in fried bacon. Food Chemistry, 168, 383-389.

Harris, R. C., Lowe, J. A., Warnes, K., \& Orme, C. E. (1997). The concentration of creatine in meat, offal and commercial dog food. Research in Veterinary Science, 62(1), 58-62.

Jamin, E. L., Riu, A., Douki, T., Debrauwer, L., Cravedi, J. P., Zalko, D., \& Audebert, M (2013). Combined genotoxic effects of a polycyclic aromatic hydrocarbon (B(a) $\mathrm{P})$ and an heterocyclic amine (PhIP) in relation to colorectal carcinogenesis. PLoS ONE, 8(3), e58591.

Kondjoyan, A., Chevolleau, S., Greve, E., Gatellier, P., Sante-Lhoutellier, V., Bruel, S., ... Debrauwer, L. (2010a). Formation of heterocyclic amines in slices of Longissimus thoracis beef muscle subjected to jets of superheated steam. Food Chemistry, 119 (1), 19-26.

Kondjoyan, A., Chevolleau, S., Greve, E., Gatellier, P., Sante-Lhoutellier, V., Bruel, S., .. Debrauwer, L. (2010b). Modelling the formation of heterocyclic amines in slices of Longissimus thoracis and Semimembranosus beef muscles subjected to jets of hot air. Food Chemistry, 123(3), 659-668.

Kondjoyan, A., Kohler, A., Realini, C. E., Portanguen, S., Kowalski, R., Clerjon, S., ... Debrauwer, L. (2014). Towards models for the prediction of beef meat quality during cooking. Meat Science, 97, 323-331.

Mora, L., Sentandreu, M. A., \& Toldra, F. (2008). Contents of creatine, creatinine and carnosine in porcine muscles of different metabolic types. Meat Science, 79(4), $709-715$.

Nagao, M. (1999). A new approach to risk estimation of food-borne carcinogensheterocyclic amines-based on molecular information. Mutation Research/ Fundamental and Molecular Mechanisms of Mutagenesis, 431(1), 3-12.

Ollberding, N. J., Wilkens, L. R., Henderson, B. E., Kolonel, L. N., \& Le Marchand, L. (2012). Meat consumption, heterocyclic amines and colorectal cancer risk: The Multiethnic Cohort Study. International Journal of Cancer, 131(7), E1125-E1133.

Polak, T., Andrenšek, S., Žlender, B., \& Gašperlin, L. (2009). Effects of ageing and low internal temperature of grilling on the formation of heterocyclic amines in beef Longissimus dorsi muscle. LWT - Food Science and Technology, 42(1), 256-264.

Portanguen, S., Ikonic, P., Clerjon, S., \& Kondjoyan, A. (2014). Mechanisms of crust development at the surface of beef meat subjected to hot air: An experimental study. Food and Bioprocess Technology, 7(11), 3308-3318.

Purchas, R. W., Rutherfurd, S. M., Pearce, P. D., Vather, R., \& Wilkinson, B. H. P. (2004). Cooking temperature effects on the forms of iron and levels of several other compounds in beef Semitendinosus muscle. Meat Science, 68, 201-207.

Purchas, R. W., \& Busboom, J. R. (2005). The effect of production system and age on levels of iron, taurine, carnosine, coenzyme $\mathrm{Q}(10)$, and creatine in beef muscles and liver. Meat Science, 70(4), 589-596.

Purchas, R. W., Busboom, J. R., \& Wilkinson, B. H. (2006). Changes in the forms of iron and in concentrations of taurine, carnosine, coenzyme $Q(10)$, and creatine in beef Longissimus muscle with cooking and simulated stomach and duodenal digestion. Meat Science, 74(3), 443-449.

Zöchling, S., \& Murkovic, M. (2002). Formation of the heterocyclic aromatic amine PhIP: Identification of precursors and intermediates. Food Chemistry, 79(1) 125-134. 